Reprod. Nutr. Dévelop., 1988, 28 (1), 153-154.

\title{
Influence de l'addition de vitamines du groupe B sur la dégradation des constituants pariétaux (paille-foin-pulpe) par les microorganismes du rumen en fermenteur semi-continu
}

\section{BOUILLIER-OUDOT, A. BELFADLA, M. CANDAU}

Laboratoire de Zootechnie et des Productions Animales, Ecole Nationale Supérieure Agronomique de Toulouse, 145. Avenue de Muret, 31076 Toulouse Cedex, France.

Summary. The effect of vitamin B supplementation on cell wall degradation of straw, hay and dried sugar beet pulp has been studied with the rumen simulation technique. The addition of $B$ vitamins improved the degradation rate of straw. Small non significant differences $(P>0.05)$ were observed for hay and pulp.

Il est classique de considérer qu'il y a l'adéquation entre les synthèses de vitamines du groupe B par la micropopulation ruminale, les besoins des microorganismes et ceux des ruminants hôtes (Rérat, 1960). Des études récentes montrent cependant que diverses supplémentations vitaminiques peuvent modifier les fermentations ruménales et améliorer les performances zootechniques de l'animal (Candau et al., 1981 ; Shields et al., 1983 ; Brent et Bartley, 1984). Dans ce travail nous avons recherché les effets d'un apport journalier de vitamines B sur la dégradation microbienne de différents substrats fibreux en fermenteur semi-continu type Rusitec (Czerkawski et Breckenridge, 1977).

Matériel et méthodes. Trois aliments (paille de blé, foin de graminées et pulpe de betteraves déshydratées) sont incubés en fermenteur type Rusitec sans (Témoin) ou avec un cocktail vitaminique B (Traitement). L'inoculum provient de trois moutons alimentés avec du foin de graminées. L'aliment est introduit dans chaque sachet nylon (vide de maille $150 \mu \mathrm{m}$ ) à raison de $6 \mathrm{~g}$ de matière sèche pour la paille et le foin et $12 \mathrm{~g}$ pour la pulpe. Chaque fermenteur contient 3 sachets du même aliment dont 2 sont alternativement renouvelés chaque jour, l'un ayant séjourné $24 \mathrm{~h}$ l'autre $48 \mathrm{~h}$. Une solution minérale additionnée d'urée à raison de 321,250 et $778 \mathrm{mg} / \mathrm{l}$ pour les incubations des substrats paille, foin ou pulpe, est apportée par perfusion en continu $(0,9 \mathrm{I}$ par $24 \mathrm{~h}$ et par fermenteur). La paille est complémentée en amidon (100 $\mathrm{mg} / \mathrm{g}$ de $\mathrm{MS})$. Le cocktail vitaminique, en solution aqueuse, est introduit dans le fermenteur au moment de son ouverture. Les apports vitaminiques journaliers ainsi réalisés sont les suivants (en $\mathrm{mg} / \mathrm{kg}$ de MS d'aliment): thiamine 20 , riboflavine 20 , niacine 100 , acide pantothénique 92 , pyridoxine 20 , vitamine $B 120,15$, biotine 1 , acide folique 10 , choline 7500 et vitamine $C 1000$. Après une semaine d'adaptation, la matière organique (MO) et la teneur en constituants pariétaux (NDF) des résidus des sachets d'une part, la quantité d'acides gras volatils (AGV) produits (effluents) d'autre part sont déterminées journellement pendant 7 jours consécutifs.

Résultats et discussion. L'addition de vitamines B améliore significativement la dégradation microbienne de la paille aussi bien après $24 \mathrm{~h}$ (MO: $+32 \%$, NDF : + $34 \%$ ) qu'après $48 \mathrm{~h}$ (MO : + $17 \%$, NDF : + $16 \%$ ) (fig. 1 ) et dans une moindre mesure celle du foin après $24 \mathrm{~h}$. Le foin et la pulpe étant moins riches en parois cellulaires que la paille INDF \% de MS : paille 82, foin 65, 
pulpe 50 ) et étant dégradés plus vite (dMO $24 \mathrm{~h}$ en $\%$ de dMO $48 \mathrm{~h}$ : paille 46 , foin 70, pulpe 66), on peut émettre I'hypothèse qu'un délai de fermentation in vitro inférieur à $24 \mathrm{~h}$ permettrait de mettre en évidence un effet significatif de l'addition de vitamines $B$ sur la vitesse de dégradation de ces substrats. L'augmentation de la production d'AGV consécutive à la supplémentation vitaminique de la paille reflète l'amélioration de la dégradation de la MO de ce substrat. L'augmentation de la proportion d'acide propionique observée en présence de paille et pulpe peut être reliée aux observations de Candau et al. (1981) qui constatent pour un régime purifié une augmentation de la production de propionate aux dépens de l'acétate et du butyrate lors de l'addition d'un mélange de thiamine, riboflavine, niacine et acide pantothénique.

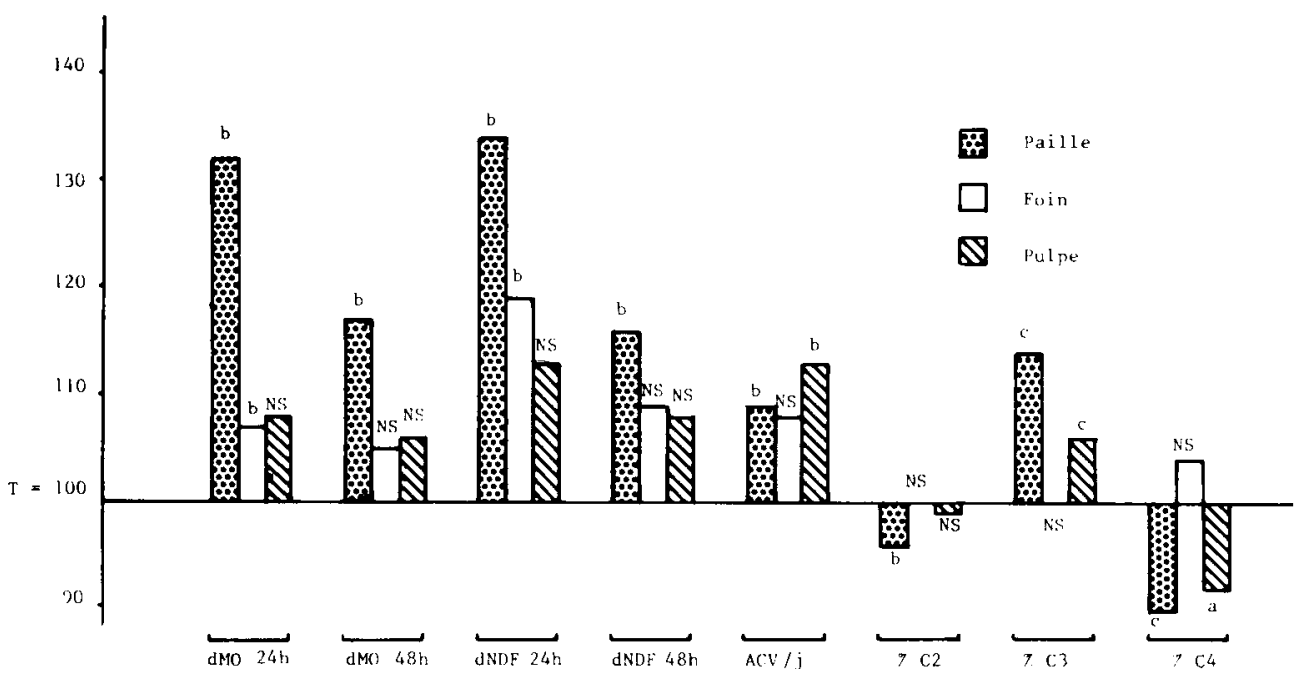

FIG. 1. - Effet de l'addition d'un cocktail vitaminique B sur la disparition de la matière organique (MO), et les parois (NDF), en Rusitec, de différents substrats fibreux et la production d'acides gras volatils (l'indice 100 correspond aux valeurs obtenues pour le témoin : T).

Signification des différences observées par rapport au témoin (T). NS $=$ Non signicatif; a = $\mathrm{P}<0,05, \mathrm{~b}=\mathrm{P}<0,01 ; \mathrm{c}=\mathrm{P}<0,001$.

En conclusion, cette expérience met en évidence l'effet positif d'un apport vitaminique sur la dégradation de paille, fourrage riche en parois cellulaires, pauvre en constituants cytoplasmiques et à faible vitesse de dégradation. Les tendances observées pour des fourrages dont la vitesse de dégradation est plus élevée demandent à être confirmées par des études de cinétique.

Brent B. E., Bartley E. E., 1984. J. anim. Sci., 59, 813-822.

randau M., Kone L., Morzières J. P., 1981. Reprod. Nutr. Dévelop., 21, 864.

Czerkawski J. W., Breckenridge G., 1977. Br. J. Nutr., 38, 371-384.

Rérat A., 1960. Synthèse et absorption des vitamines B dans le tube digestif du mouton adulte, thèse Sciences, I.N.R.A. Ed.

Shields D. R., Schaefer D. M., Perry T. W., 1983. J. anim. Sci, 57, 1576-1583. 